\title{
One-Year Update on Salivary Diagnostic of COVID-19
}

\section{OPEN ACCESS}

Edited by:

Zisis Kozlakidis,

International Agency for Research on

Cancer (IARC), France

Reviewed by:

Karolina Kaczor-Urbanowicz, University of California, Los Angeles,

United States

Angsana Phuphuakrat,

Mahidol University, Thailand

Lubomira Tóthová,

Comenius University, Slovakia

*Correspondence:

Robinson Sabino-Silva

robinsonsabino@gmail.com

Specialty section:

This article was submitted to Infectious Diseases - Surveillance,

Prevention and Treatment,

a section of the journal

Frontiers in Public Health

Received: 19 August 2020

Accepted: 31 March 2021

Published: 21 May 2021

Citation:

Caixeta DC, Oliveira SW

Cardoso-Sousa L, Cunha TM,

Goulart LR, Martins MM, Marin LM,

Jardim ACG, Siqueira $W L$ and

Sabino-Silva R (2021) One-Year

Update on Salivary Diagnostic of

COVID-19.

Front. Public Health 9:589564.

doi: 10.3389/fpubh.2021.589564

\section{Douglas Carvalho Caixeta ${ }^{1}$, Stephanie Wutke Oliveira ${ }^{1,2}$, Leia Cardoso-Sousa ${ }^{1}$, Thulio Marquez Cunha ${ }^{3}$, Luiz Ricardo Goulart ${ }^{4}$, Mario Machado Martins ${ }^{4}$, Lina Maria Marin ${ }^{5}$, Ana Carolina Gomes Jardim ${ }^{6,7}$, Walter Luiz Siqueira ${ }^{5}$ and Robinson Sabino-Silva ${ }^{1 *}$}

1 Innovation Center in Salivary Diagnostic and Nanotheranostics, Department of Physiology, Institute of Biomedical Sciences, Federal University of Uberlandia, Uberlandia, Brazil, ${ }^{2}$ School of Dentistry, Federal University of Uberlandia, Uberlandia, Brazil, ${ }^{3}$ School of Medicine, Federal University of Uberlandia, Uberlandia, Brazil, ${ }^{4}$ Institute of Genetics and Biochemistry, Federal University of Uberlandia, Uberlandia, Brazil, ${ }^{5}$ College of Dentistry, University of Saskatchewan, Saskatoon, SK, Canada, ${ }^{6}$ Laboratory of Virology, Institute of Biomedical Science, Federal University of Uberlandia, Uberlandia, Brazil, ${ }^{7}$ São Paulo State University, Institute of Biosciences, Humanities and Exact Sciences, São José Do Rio Preto, Brazil

Background: Coronavirus disease 2019 (COVID-19) is a global health problem, which is challenging healthcare worldwide. In this critical review, we discussed the advantages and limitations in the implementation of salivary diagnostic platforms of COVID-19. The diagnostic test of COVID-19 by invasive nasopharyngeal collection is uncomfortable for patients and requires specialized training of healthcare professionals in order to obtain an appropriate collection of samples. Additionally, these professionals are in close contact with infected patients or suspected cases of COVID-19, leading to an increased contamination risk for frontline healthcare workers. Although there is a colossal demand for novel diagnostic platforms with non-invasive and self-collection samples of COVID-19, the implementation of the salivary platforms has not been implemented for extensive scale testing. Up to date, several cross-section and clinical trial studies published in the last 12 months support the potential of detecting SARS-CoV-2 RNA in saliva as a biomarker for COVID-19, providing a self-collection, non-invasive, safe, and comfortable procedure. Therefore, the salivary diagnosis is suitable to protect healthcare professionals and other frontline workers and may encourage patients to get tested due to its advantages over the current invasive methods. The detection of SARS-CoV-2 in saliva was substantial also in patients with a negative nasopharyngeal swab, indicating the presence of false negative results. Furthermore, we expect that salivary diagnostic devices for COVID-19 will continue to be used with austerity without excluding traditional gold standard specimens to detect SARS-CoV-2.

Keywords: nasopharyngeal swabs, saliva, diagnostic test, salivary diagnostic, SARS-CoV-2, COVID-19 


\section{INTRODUCTION}

The World Health Organization (WHO) indicates the pivotal importance of mass testing in the find-test-trace-isolatesupport strategy to contain COVID-19 transmission (1). The increase in massive testing capacity coupled with artificial intelligence multidisciplinary data should be used to prevent and combat the negative effects of COVID-19 and strengthen global health public systems to improve COVID-19 response (2). The National Institute of Health supports a rapid scaling up of SARS-CoV-2-detecting tests in the United States (3); however, the need for better diagnostic tests with high sensitivity has been considered critical to mitigate and suppress the spread of COVID-19 (4). Novel continued efforts need to be performed to reduce the presence of false-negative molecular testing in presymptomatic and asymptomatic subjects, as well as the presence of hospitalized patients with initial false-negative testing and clinical signs and symptoms consistent with SARS-CoV-2 infection (4).

In this critical review, at the salivary SARS-CoV-2 detection's 1 -year mark, we discussed the advantages and limitations in the implementation of salivary diagnosis of COVID-19 and point out some recommendations to this potential application to provide a comprehensive summary on the scientific advances performed in the last 12 months. The diagnostic test for COVID19 by invasive nasopharyngeal collection is uncomfortable for the patients and requires specialized training of the frontline workers in order to perform an appropriate collection of samples. Additionally, these frontline professionals are in close contact with infected patients or suspected cases of COVID-19, leading to increased morbimortality of healthcare workers. It imposes the development of new strategies for COVID-19 diagnosis; however, despite the colossal demand for novel diagnostic platforms with non-invasive and self-collection samples of COVID-19, the accuracy of salivary SARS-CoV-2 platforms are still not wellelucidated. The pivotal impact on social, health, economic, and educational fields in a global emergency due to COVID-19 makes it more challenging to compare the advantages and limitations in implementing novel potential salivary platforms $(1,2,4)$.

\section{BACKGROUND}

The coronavirus disease 2019 (COVID-19) is an international public health emergency, which also impacts social, economic, and educational aspects worldwide. The outbreak of COVID-19 is caused by the severe acute respiratory syndrome coronavirus 2 (SARS-CoV-2), which has been spread across all continents with more than 117 million cases and $\sim 2.5$ million deaths (5). The centers for disease control and prevention around the world have recommended testing for SARS-CoV-2 in upper respiratory specimens.

The COVID-19 diagnostic is mainly based on the detection of SARS-CoV-2 by real-time polymerase chain reaction (RT-PCR). The sensitivity of this gold standard test is higher in symptomatic than in asymptomatic COVID-19 subjects (6). Besides, the false-negative results have uncertain frequency especially in the incubation period of the disease. Although SARS-CoV-2 RNA detection in the nasopharyngeal swab was reported as the gold standard method for COVID-19 diagnosis, sample collection by this method requires that healthcare frontline workers are in close contact with infected patients or suspected cases of COVID19. Besides, this specimen-collecting procedure is invasive and inconvenient for patients, and it requires specialized training for healthcare workers (7).

Salivary biomarkers are an alternative method to other invasive procedures in the early diagnostic of systemic diseases (8). The collection of saliva samples represents a non-invasive, convenient, and easy self-collection method, with no direct contact between healthcare workers and patients. Saliva contains more than 3,000 proteins, 3,000 mRNA, 50 microRNAs, hundreds of metabolites, and more than 700 species of microorganisms such as viruses (9). The 198 extracellular RNAs (ExRNAs) detected in saliva were also considered potential biomarkers for systemic and oral diseases. In this context, salivary exRNA related to SARS-CoV-2 infection could be used to develop novel salivary platforms of COVID-19 $(10,11)$. Previously, we detailed the potential of salivary diagnosis for COVID-19 (12), which was confirmed in several studies by detecting SARSCoV-2 in human saliva (13-37) and in saliva associated with oropharyngeal fluid $(38,39)$. SARS-CoV-2 was also detected in animal models of COVID-19. The viral RNA was detected in saliva and nasal washes from 2 to 8 days post-infection of infected ferrets as an animal model of COVID-19 (40). In this context, analysis of SARS-CoV-2 RNA from saliva can provide clues in the early diagnosis of COVID-19. Higher viral loads of SARS$\mathrm{CoV}-2$ in oropharyngeal fluid mixed with saliva were detected on symptom onset, which then gradually declined toward the detection limit until 25 days after symptoms started $(39,41)$.

\section{FUTURE DIRECTIONS}

As the landscape of SARS-CoV-2 diagnosis comprises limitations for the current gold standard diagnosis methods and potential benefits for novel applications in COVID-19 diagnosis, a critical evaluation on the advantages and limitations of concurrent emerging salivary diagnosis is mandatory.

\section{Search Strategy and Study Selection}

We searched three electronic databases, PubMed, LILACS, and Google Scholar, from February 2020 when the SARS-CoV-2 was first indicated in saliva $(12,38)$ until February 2021. The selected keywords were COVID-19, coronavirus, SARS-CoV-2, saliva, and nasopharyngeal swabs. We selected studies that analyzed the accuracy and sensitivity of saliva compared with nasopharyngeal swabs for SARS-CoV-2 detection by RT-PCR. Positive detection of SARS-CoV-2 in saliva or nasopharyngeal fluid was considered as a reference standard.

Table 1 compares the sensitivity of nasopharyngeal and salivary samples in SARS-CoV-2 RNA detection using RTPCR and points out the presence of samples negative in nasopharyngeal swab and positive in saliva, which indicates the presence of false-negative results. 
TABLE 1 | Sensitivity of COVID-19 salivary diagnosis comparing to nasopharyngeal swab (NPS) specimens.

\begin{tabular}{|c|c|c|c|c|c|c|}
\hline References & $\begin{array}{c}\text { Total } \\
\text { samples }\end{array}$ & $\begin{array}{c}\text { Positive } \\
\text { (NPS+Saliva) }\end{array}$ & Negative & $\begin{array}{l}\text { Sensitivity } \\
\text { Saliva }\end{array}$ & $\begin{array}{l}\text { Sensitivity } \\
\text { NPS }\end{array}$ & $\begin{array}{c}\text { Percentage of Saliva } \\
+ \text { and NPS - }\end{array}$ \\
\hline Rao et al. (30) & 217 & 160 & 57 & $\begin{array}{c}93.1 \% \\
(149 / 160)\end{array}$ & $\begin{array}{c}52.5 \% \\
(84 / 160)\end{array}$ & $\begin{array}{c}47.5 \% \\
(76 / 160)\end{array}$ \\
\hline Caulley et al. (17) & 272 & 13 & 259 & $\begin{array}{l}84.6 \% \\
(11 / 13)\end{array}$ & $\begin{array}{l}61.5 \% \\
(8 / 13)\end{array}$ & $\begin{array}{l}38.5 \% \\
(5 / 13)\end{array}$ \\
\hline Senok et al. (32) & 401 & 35 & 366 & $\begin{array}{c}80 \% \\
(28 / 35)\end{array}$ & $\begin{array}{l}74.3 \% \\
(26 / 28)\end{array}$ & $\begin{array}{l}25.7 \% \\
(9 / 35)\end{array}$ \\
\hline Uwamino et al. (35) & 196 & 58 & 138 & $\begin{array}{l}74.1 \% \\
(43 / 58)\end{array}$ & $\begin{array}{c}81 \% \\
(47 / 58)\end{array}$ & $\begin{array}{c}19 \% \\
(11 / 58)\end{array}$ \\
\hline Moreno-Contreras et al. (27) & 71 & 34 & 37 & $\begin{array}{l}73.5 \% \\
(25 / 34)\end{array}$ & $\begin{array}{c}82.3 \\
(28 / 34)\end{array}$ & $\begin{array}{l}17.6 \% \\
(6 / 34)\end{array}$ \\
\hline Yokota et al. (37) & 1,924 & 52 & 1,872 & $\begin{array}{l}92.3 \% \\
(48 / 52)\end{array}$ & $\begin{array}{l}88.5 \% \\
(46 / 52)\end{array}$ & $\begin{array}{l}11.5 \% \\
(6 / 52)\end{array}$ \\
\hline Jamal et al. (21) & 91 & 72 & 19 & $\begin{array}{l}72.2 \% \\
(52 / 72)\end{array}$ & $\begin{array}{l}88.9 \% \\
(64 / 72)\end{array}$ & $\begin{array}{l}11.1 \% \\
(8 / 72)\end{array}$ \\
\hline Iwasaki et al. (20) & 76 & 10 & 66 & $\begin{array}{l}90 \% \\
(9 / 10)\end{array}$ & $\begin{array}{l}90 \% \\
(9 / 10)\end{array}$ & $\begin{array}{l}10 \% \\
(1 / 10)\end{array}$ \\
\hline Pasomsub et al. (28) & 200 & 21 & 179 & $\begin{array}{l}85.7 \% \\
(18 / 21)\end{array}$ & $\begin{array}{l}90.5 \% \\
(19 / 21)\end{array}$ & $\begin{array}{l}9.5 \% \\
(2 / 21)\end{array}$ \\
\hline Torres et al. (34) & 943 & 108 & 835 & $\begin{array}{c}42.6 \% \\
(46 / 108)\end{array}$ & $\begin{array}{c}92.6 \% \\
(100 / 108)\end{array}$ & $\begin{array}{c}7.4 \% \\
(8 / 108)\end{array}$ \\
\hline Hanson et al. (19) & 354 & 86 & 268 & $\begin{array}{l}94.2 \% \\
(81 / 86)\end{array}$ & $\begin{array}{c}93 \% \\
(80 / 86)\end{array}$ & $\begin{array}{c}7 \% \\
(6 / 86)\end{array}$ \\
\hline Kandel et al. (22) & 429 & 46 & 383 & $\begin{array}{l}91.3 \% \\
(42 / 46)\end{array}$ & $\begin{array}{l}93.5 \% \\
(43 / 46)\end{array}$ & $\begin{array}{l}6.5 \% \\
(3 / 46)\end{array}$ \\
\hline Landry et al. (23) & 124 & 35 & 89 & $\begin{array}{l}85.7 \% \\
(30 / 35)\end{array}$ & $\begin{array}{l}94.3 \% \\
(33 / 35)\end{array}$ & $\begin{array}{l}5.7 \% \\
(2 / 35)\end{array}$ \\
\hline Babady et al. (14) & 87 & 18 & 69 & $\begin{array}{l}94.4 \% \\
(17 / 18)\end{array}$ & $\begin{array}{l}94.4 \% \\
(17 / 18)\end{array}$ & $\begin{array}{l}5.5 \% \\
(1 / 18)\end{array}$ \\
\hline Miller et al. $(26)^{\star}$ & 91 & 36 & 55 & $\begin{array}{l}97.2 \% \\
(35 / 36)\end{array}$ & $\begin{array}{l}94.4 \% \\
(34 / 36)\end{array}$ & $\begin{array}{l}5.5 \% \\
(2 / 36)\end{array}$ \\
\hline Skolimowska et al. (33) & 131 & 19 & 112 & $\begin{array}{l}84.2 \% \\
(16 / 19)\end{array}$ & $\begin{array}{l}94.7 \% \\
(18 / 19)\end{array}$ & $\begin{array}{l}5.3 \% \\
(1 / 19)\end{array}$ \\
\hline Altawalah et al. (13) & 848 & 361 & 487 & $\begin{array}{c}84.2 \% \\
(304 / 361)\end{array}$ & $\begin{array}{c}95.3 \% \\
(344 / 361)\end{array}$ & $\begin{array}{c}4.7 \% \\
(17 / 361)\end{array}$ \\
\hline Matic et al. (24) & 74 & 22 & 52 & $\begin{array}{l}72.7 \% \\
(16 / 22)\end{array}$ & $\begin{array}{l}95.4 \% \\
(21 / 22)\end{array}$ & $\begin{array}{l}4.5 \% \\
(1 / 22)\end{array}$ \\
\hline Chau et al. (18) & 27 & 28 & NA & $\begin{array}{c}75 \% \\
(21 / 28)\end{array}$ & $\begin{array}{l}96.4 \% \\
(27 / 28)\end{array}$ & $\begin{array}{l}3.6 \% \\
(1 / 28)\end{array}$ \\
\hline Vaz et al. (36) & 155 & 73 & 82 & $\begin{array}{l}94.5 \% \\
(69 / 73)\end{array}$ & $\begin{array}{l}97.3 \% \\
(71 / 73)\end{array}$ & $\begin{array}{l}2.7 \% \\
(2 / 73)\end{array}$ \\
\hline Barat et al. (15) & 459 & 38 & 421 & $\begin{array}{l}81.6 \% \\
(31 / 38)\end{array}$ & $\begin{array}{l}97.4 \% \\
(37 / 38)\end{array}$ & $\begin{array}{l}2.6 \% \\
(1 / 38)\end{array}$ \\
\hline McCormick-Baw et al. (25) & 156 & 50 & 106 & $\begin{array}{c}96 \% \\
(48 / 50)\end{array}$ & $\begin{array}{c}98 \% \\
(49 / 50)\end{array}$ & $\begin{array}{c}2 \% \\
(1 / 50)\end{array}$ \\
\hline Bhattacharya et al. (16) & 74 & 58 & 16 & $\begin{array}{l}91.4 \% \\
(53 / 58)\end{array}$ & $\begin{array}{c}100 \% \\
(58 / 58)\end{array}$ & $\begin{array}{c}0 \% \\
(0 / 58)\end{array}$ \\
\hline Ranoa et al. (29) & 100 & 9 & 91 & $\begin{array}{c}100 \% \\
(9 / 9)\end{array}$ & $\begin{array}{c}100 \% \\
(9 / 9)\end{array}$ & $\begin{array}{c}0 \% \\
(0 / 9)\end{array}$ \\
\hline Rutgers (31) & 53 & 26 & 27 & $\begin{array}{c}100 \% \\
(26 / 26)\end{array}$ & $\begin{array}{c}100 \% \\
(26 / 26)\end{array}$ & $\begin{array}{c}0 \% \\
(0 / 26)\end{array}$ \\
\hline Overall & 7,553 & 1,468 & 6,086 & $\begin{array}{c}83.6 \% \\
(1,227 / 1,468)\end{array}$ & $\begin{array}{c}88.4 \% \\
(1,298 / 1,468)\end{array}$ & $\begin{array}{c}11.6 \% \\
(171 / 1,468)\end{array}$ \\
\hline
\end{tabular}

"The specificity of both salivary and nasopharyngeal (NPS) swabs were 100\%. Considering the presence of false-negative results with NPS, a positive detection of SARS-CoV-2 in saliva or nasopharyngeal fluid was considered as a positive standard reference. 


\section{Limitations of SARS-CoV-2 Detection in Nasopharyngeal Specimens}

Although the nasopharyngeal swab tests have been considered as gold standard specimens, multisite assessment or other specimens for SARS-CoV-2 diagnosis have been suggested to reduce false-negative test results and to increase testing capacity (42), especially due to limitations in low-middle income countries (LMICs) (43). Nasopharyngeal collection is performed using a flexible plastic swab with a nylon tip, which is inserted into the nostrils until the healthcare worker observes resistance. Subsequently, the swab is rotated three times in the nasopharynx and removed after $5 \mathrm{~s}$, a procedure which is considered invasive and uncomfortable $(44,45)$. However, the swab collection protocol can be different in each country. Appropriate nasopharyngeal swab collection is more difficult in children and patients with a deviated nasal septum or coagulopathy (46). The sputum is another respiratory specimen tested to be used in COVID-19 diagnosis. Due to the limitations of sampling, sputum collection was used in possibly only one third of COVID-19 patients, which reveals a robust restriction of this diagnostic method $(12,38)$. Self-collection of samples from suspected cases of COVID-19 or infected patients is still limited and the direct contact between healthcare workers and patients during the standard collection procedures resulted in about $20 \%$ of the healthcare workforce becoming infected, and some deaths were reported (47). Frontline workers may experience intense anxiety and additional adverse emotion due to the risk of contamination during the collection procedure (48). Although most studies showed higher levels of the virus in nasopharyngeal specimens compared with saliva, lower levels of SARS-CoV-2 in nasopharyngeal swabs can result in falsenegative outcomes due to inaccurate collection (48). The personal protective equipment and creation of exclusive sampling rooms have been reported as tools capable of enhancing the protection of frontline workers $(47,48)$. Currently, COVID-19 cases have been significantly increasing worldwide, overloading national health systems. Furthermore, the situation might be even worse in LMICs, since there is a scarcity of trained healthcare and other frontline workers to face the COVID-19 pandemic (49). Taken together, these issues demonstrate the critical demand for new approaches for COVID-19 diagnosis.

\section{The Potential of Salivary Diagnosis of COVID-19}

The enthusiasm in developing new salivary platforms for COVID-19 diagnosis and monitoring is comprehensible; however, the true accuracy of these new protocols to detect SARS-CoV-2 in saliva has been discussed in several scenarios such as during the incubation period, the viral response phase, and the host inflammatory phase of symptomatic patients. Besides, the diagnostic sensitivity levels in COVID-19 asymptomatic patients also remain unclear in both salivary and nasopharyngeal specimens. It is important to emphasize that the implementation of salivary diagnosis for COVID-19 before a comprehensive knowledge of its limitation could promote future issues about the application of salivary diagnostic tests to other systemic diseases. However, the colossal demand for novel diagnostic platforms for COVID-19 with non-invasive and self-collection samples could be used after the creation of a well-designed strategic plan for its implementation until this true efficacy will be completely investigated.

\section{Preponderance of Reviews and Letters Over Primary Clinical Trials}

The most remarkable data on COVID-19 salivary diagnosis implementation is the unbalanced number of published clinical trials or reviews and letters. PubMed reveals 20 cross-sectional and case-control designed studies, five cross-sectional studies with no control subjects, and more than 200 reviews and letters published from February 2020 up to February 2021. Additionally, there are 14 additional cross-sectional studies that evaluated the oropharyngeal fluid mixed with saliva as a diagnostic fluid for COVID-19. It suggests that opinions concerning salivary diagnostic platforms have been consolidated primarily from letters and reviews. On the other hand, it is important to emphasize that cross-sectional studies with salivary diagnostics indicated a higher correlation of sensitivity compared with the gold standard nasopharyngeal samples in COVID-19 diagnosis. We performed this critical review due to the limitations concerning current reviews focusing on the counterbalance between the inevitable obstacles and encouraging results of COVID-19 salivary diagnosis.

\section{Sample Size of Studies}

In order to obtain a more robust comparison of saliva with gold standard specimens, a limited number of comparative studies and lower sample sizes have been overcome in these 12 months after SARS-CoV-2 detection in saliva (38) Altogether, the total number of salivary samples (non-infected subjects and COVID-19 patients), which was compared with gold standard nasopharyngeal respiratory specimens was 7,553. In this context, 5,172 subjects were from published studies/original articles, 53 subjects from the FDA emergence-approved study, 191 subjects from preprint articles, 559 subjects from short communications/brief reports, and 1,578 subjects from letters to the editor. To detect the salivary sensitivity 1,468 salivary and/or NPS-positive samples from COVID-19-infected patients were used and evaluated in this review (Table 1).

\section{The Relevance of Specificity in SARS-CoV-2 Detection}

In general, the absence of analysis in control subjects can be considered a negative condition; however, the main limitation in the use of RT-PCR tests is the detection of RNA in levels near the sensitivity limits. The detection of unspecific RNA is not a classical limitation of RT-PCR tests (50), which is considered $100 \%$ specific due to the intrinsic characteristics of this platform (51). It must be considered that the presence of SARS-CoV-2 RNA in saliva and negative results in nasopharyngeal samples analyzed by RT-PCR cannot be classified as false positive, but a misclassification of nasopharyngeal samples. This pivotal view is well-documented in a previous study that showed $71 \%$ of matched detection of SARS-CoV-2 RNA in saliva and 
nasopharyngeal swabs, $21 \%$ only in saliva, and $8 \%$ only in nasopharyngeal swabs (52). It can be related with the limitations in nasopharyngeal swab procedure and/or with low produced nasopharyngeal mucous secretion in COVID-19 patients. In this new pandemic era, the centers for disease control and prevention worldwide took maximal efforts to establish reference standards for COVID-19 diagnosis in a fast and efficient way, based on the outbreak of severe acute respiratory syndrome (SARS) in 2003 (53). It is well-recognized that updates in COVID-19 diagnosis protocols are crucial, and the reference standards are not perfect, especially in samples collected in the 1st days after infection (54). The procedures related to sample preservation and RNA extraction were reported in all included studies, and it seems suitable, and presumably these factors did not influence the results. In this context, it is important to emphasize that the absence of a control group in the studies with oropharyngeal fluid mixed with saliva is not a significant limitation $(38,39,55-57)$. The reference standard using nasopharyngeal specimens was considered as an unsolved issue that needs imperative debate to increase confidence in COVID-19 tests (54).

\section{Saliva Collection and Its Correlation With Sensitivity}

The pioneer study that detected viable SARS-CoV-2 in oral fluid promoted a paradigm shift in diagnosis, monitoring, and infection control for COVID-19 (38). However, the sensitivity of salivary SARS-CoV-2 RNA to diagnose COVID-19 needs to be carefully checked because some data are based on trials designed to evaluate oropharyngeal fluid mixed with saliva $(38,39,57-59)$. In classical studies with salivary collection, the patient is not required to cough out fluid from their throat. Frequently, total saliva is collected from the mouth under an unstimulated or stimulated flow rate (9). Some collection devices were also developed to collect saliva specifically from parotid, submandibular/sublingual, and minor and palatine glands (9). Here, this review considered studies that collected saliva by the traditional drooling technique and without coughing into a container. Table 1 shows a similar sensitivity to detect SARSCoV-2 RNA undergoing paired collection of saliva and NPS. SARS-CoV-2 RNA was detected overall in $83.6 \%(1,227 / 1,468)$ of saliva samples and also in $88.4 \%(1,298 / 1,468)$ of samples of NPS, which supports the potential of salivary SARS-CoV-2 RNA as a biomarker for COVID-19 in a preliminary analysis. We also highlight a substantial salivary detection of SARS-CoV-2 in patients with a negative nasopharyngeal swab $(11.6 \%, 171 / 1,468)$, indicating an expressive indication of false-negative results with gold standard specimens. Thus, based on these data, we suggest that saliva is an accurate sample to be used for a mass screening test, and this biofluid could be used to reduce the rate of false negatives in the clinical performance of COVID-19 diagnostic tests. We also observed that the majority of articles analyzed unstimulated saliva, which avoids a potential dilution of the SARS-CoV-2, which could occur in mouth rinsing or stimulated saliva collection (60).

\section{The Importance of Home- and Self-Sample Collection}

It was indicated that the primary choice for sampling during illness experience is home-based tests compared with clinicbased strategies. The higher compliance to test for SARS-CoV2 was verified when a lower degree of contact with frontline healthcare workers was required to collect samples: as expected, home testing was the most preferred, followed by tests in drivethrough sets and, subsequently, hospital-based testing. It is crucial to provide self-saliva collection and home-based tests to suspected cases of COVID-19 as profitable strategies in order to guarantee the social distance of the population. It also contributes to reduce direct contact with frontline workers, which offers a potential for early diagnosis due to the hierarchy of willingness to test for COVID-19. The self-sample collection and home-based tests should be validated as soon as possible to be applied in public and private healthcare systems (61).

\section{Spectrum of Patients}

In order to provide a suitable spectrum of COVID-19 patients with distinct severity of diseases, it is important to envisage patients searching for a diagnostic test in the onset of symptoms and in the late stage of the disease. Bearing in mind that the higher salivary SARS-CoV-2 levels occur during the acute phase of disease with gradual decline after symptom onset (39), it is important to point out the limitations of longitudinal analysis with SARS-CoV-2 level in asymptomatic COVID-19 subjects. In this context, the temporal analysis of SARS-CoV-2 viral load in saliva should receive more attention among asymptomatic and non-hospitalized COVID-19 patients, which could be pivotal for the translation of salivary tests in the clinic. However, the current gold standard protocols are also unable to raise this query (54). The comparison between sensitivity shown in Table 1, in different studies, reported a limited heterogeneity, which should not be ignored to improve this new potential gold standard protocol.

\section{Obstacles to SARS-CoV-2 RNA Extraction From Saliva and New Applications}

A critical hurdle for salivary diagnosis may be the broadspectrum validation in COVID-19 patients during the incubation period, the viral response phase, and the host inflammatory phase in asymptomatic and symptomatic patients. It has been proposed that patients can be infected and after 24 to 72 hours the onset of symptoms could occur. About $50 \%$ of the transmission of cases is from asymptomatic COVID-19 individuals. The viral levels of SARS-CoV-2 RNA are presumably detected in nasopharyngeal swabs before or sooner than symptom onset, which is a leading challenge in the diagnosis, spread, and containment of COVID19 (6).

Some critical issues in the isolation of RNA methods to process saliva are unique to this biofluid. The know-how and practice to pipette a biofluid with higher density could explain the discrepancy between the overall sensitivity in different studies. Some protocols indicated the dilution of saliva in a standard liquid as that occurring in nasopharyngeal swabs. This action can 
change the SARS-CoV-2 concentration and reduce the sensitivity of tests. In this context, the higher saliva density that makes pipetting difficult, tooth-brushing contaminants, and changes in volume are parameters that could interfere with the result (62). In general, the use of the magnetic bead methodology showed good results for saliva sensitivity, $97.2 \%$ (26), possibly due to the RNA extraction insulation kit used. In addition, the enzymes present in saliva also makes RNA naturally degrade, so choosing a more robust methodology is important for the sensitivity and specificity of the experiment (26).

Various methods are available to extract RNA from saliva, such as methods using phenol and guanidinium isothiocyanate, or commercially available silica membrane spin columns or magnetic bead-based RNA isolation kits (63). Other molecular diagnostic methods, such as reverse transcription-loop-mediated isothermal amplification (RT-LAMP), have also been reported as useful for diagnosing COVID-19 in settings of point-of care testing (64-66). Rapid and extraction-free detection of SARS-CoV-2 from saliva by colorimetric RT-LAMP is a simple, sensitive, rapid, and cost-effective approach with broad potential to expand diagnostic testing for the virus causing COVID-19 $(67,68)$. Although full validation on additional clinical samples is necessary before such an assay can be widely used, a few studies have evaluated this technique. These preliminary results demonstrate a promising approach to overcome the current bottlenecks that limit widespread testing.

Furthermore, the sequencing of the genome using salivary samples from COVID-19 patients could contribute in the incorporation of new targets (69), identification of the new SARS-CoV-2 variants of concern (as B.1.1.7 emerged in the United Kingdom, B.1.351 was first identified in South Africa, and P.1 emerged in Brazil) (70, 71), or even in the identification of critical mutations (72). In addition, a nanopore sequencing analysis of saliva suggests that host factors play a more important role in the clinical outcome than viral genetic variation (69), as demonstrated by emerging clinical studies (73).

\section{FINAL REMARKS}

These tests seem to be in agreement with FDA emergence approval, which includes a home collection of saliva to diagnose COVID-19 when indicated by a healthcare provider. Up until now, the FDA had authorized at least five salivary tests for

\section{REFERENCES}

1. Burki T. Mass testing for COVID-19. Lancet Microbe. (2020) 1:e317. doi: 10.1016/S2666-5247(20)30205-6

2. Donia A, Hassan S-u, Zhang X, Al-Madboly L, Bokhari H. COVID-19 crisis creates opportunity towards global monitoring and surveillance. Pathogens. (2021) 10:256. doi: 10.3390/pathogens10030256

3. Tromberg BJ, Schwetz TA, Pérez-Stable EJ, Hodes RJ, Woychik RP, Bright RA, et al. Rapid scaling up of covid-19 diagnostic testing in the United States the NIH RADx initiative. (2020) 383:1071-7. doi: 10.1056/NEJMsr2022263

4. Manabe YC, Sharfstein JS, Armstrong K. The need for more and better testing for COVID-19. JAMA. (2020) 324:2153-4. doi: 10.1001/jama.2020.21694
COVID-19 diagnosis. The patients are also informed that a negative result is not a guarantee of the absence of COVID19 infection. However, due to the high specificity of RTPCR analysis, the detection of SARS-CoV-2 in saliva can be acceptable when the diagnostic test for COVID-19 is positive. We also highlight a substantial salivary detection of SARS-CoV2 in patients with a negative nasopharyngeal swab (11.6\%), indicating an expressive indication of false-negative results with gold standard specimens. Besides, the higher compliance to test for SARS-CoV-2 under reduced direct contact, requiring the collection of saliva, may contribute to an early diagnosis of COVID-19, resulting in optimal clinical care, encouraging isolation and reducing the spread of the disease. In this regard, the potential implementation of salivary SARS-CoV-2 diagnosis under a pandemic situation and social, health, economic, and educational issues due to COVID-19 is an additional challenge. These results support the potential of SARS-CoV-2 RNA as a biomarker for COVID-19, providing a self-collection, noninvasive, safe, and comfortable analysis, suitable to protect dentists, dental assistants, dental hygienists, and other frontline workers with self-collection and/or home collection saliva samples. Furthermore, we expect that salivary diagnostic devices for COVID-19 will continue to be used with austerity without excluding traditional gold standard specimens to detect SARSCoV-2.

\section{AUTHOR CONTRIBUTIONS}

All authors listed have made a substantial, direct and intellectual contribution to the work, and approved it for publication.

\section{FUNDING}

This research was supported by a grant from CAPESPrevention and Combat of Outbreaks, Endemics, Epidemics, and Pandemics (\#\#88887.506792/2020-00), CAPES/CNPq (\#458143/2014), FAPEMIG (\#APQ-02872-16), and the Federal University of Uberlandia and National Institute of Science and Technology in Theranostics and Nanobiotechnology (CNPq Process N.: 465669/2014-0). This research was supported by the Canadian Institutes of Health Research (CIHR grant nos. 106657 and 97577). DC received a fellowship from FAPEMIG. RS-S received a fellowship from FAU/UFU and PrInt CAPES/UFU.
5. Dong E, Du H, Gardner L. An interactive web-based dashboard to track COVID-19 in real time. Lancet Infect Dis. (2020) 20:533-4. doi: 10.1016/S1473-3099(20)30120-1

6. Gandhi RT, Lynch JB, del Rio C. Mild or moderate covid-19. N Engl J Med. (2020) 383:1757-66. doi: 10.1056/NEJMcp2009249

7. Chan JF, Yuan S, Kok KH, To KK, Chu H, Yang J, et al. A familial cluster of pneumonia associated with the 2019 novel coronavirus indicating person-to-person transmission: a study of a family cluster. Lancet. (2020) 395:514-23. doi: 10.1016/S0140-6736(20) 30154-9

8. Zhang CZ, Cheng XQ, Li JY, Zhang P, Yi P, Xu X, et al. Saliva in the diagnosis of diseases. Int J Oral Sci. (2016) 8:133-7. doi: 10.1038/ijos.2016.38 
9. Dawes C, Wong DTW. Role of saliva and salivary diagnostics in the advancement of oral health. J Dent Res. (2019) 98:13341. doi: 10.1177/0022034518816961

10. Kaczor-Urbanowicz KE, Kim Y, Li F, Galeev T, Kitchen RR, Gerstein $\mathrm{M}$, et al. Novel approaches for bioinformatic analysis of salivary RNA sequencing data for development. Bioinformatics. (2018) 34:1-8. doi: 10.1093/bioinformatics/btx504

11. Preissner KT, Fischer S, Deindl E. Extracellular RNA as a versatile DAMP and alarm signal that influences leukocyte recruitment in inflammation and infection. Front Cell Dev Biol. (2020) 8:1-24. doi: 10.3389/fcell.2020.619221

12. Sabino-Silva R, Jardim ACG, Siqueira WL. Coronavirus COVID-19 impacts to dentistry and potential salivary diagnosis. Clin Oral Investig. (2020) 24:161921. doi: 10.1007/s00784-020-03248-x

13. Altawalah H, AlHuraish F, Alkandari WA, Ezzikouri S. Saliva specimens for detection of severe acute respiratory syndrome coronavirus 2 in Kuwait: a cross-sectional study. J Clin Virol. (2020) 132:104652. doi: 10.1016/j.jcv.2020.104652

14. Babady NE, McMillen T, Jani K, Viale A, Robilotti EV, Aslam A, et al. Performance of severe acute respiratory syndrome coronavirus 2 real-time RT-PCR tests on oral rinses and saliva samples. J Mol Diagnostics. (2021) 23:3-9. doi: 10.1016/j.jmoldx.2020.10.018

15. Barat B, Das S, De Giorgi V, Henderson DK, Kopka S, Lau AF, et al. Pooled saliva specimens for SARS-CoV-2 testing. J Clin Microbiol. (2020) 59:8. doi: 10.1128/JCM.02486-20

16. Bhattacharya D, Parai D, Rout UK, Dash P, Nanda RR, Dash GC, et al. Saliva for diagnosis of SARS-CoV-2: first report from India. J Med Virol. (2020) 93:2529-33. doi: 10.1002/jmv.26719

17. Caulley L, Corsten M, Eapen L, Whelan J, Angel JB, Antonation K, et al. Salivary detection of COVID-19. Ann Internal Med. (2021) 174:1313. doi: 10.7326/M20-4738

18. Chau NVV, Thanh Lam V, Thanh Dung N, Yen LM, Minh NNQ, Hung LM, et al. The natural history and transmission potential of asymptomatic SARSCoV-2 infection. Clin Infect Dis. (2020) 71:2679-87. doi: 10.1093/cid/ciaa711

19. Hanson KE, Barker AP, Hillyard DR, Gilmore N, Barrett JW, Orlandi RR, et al. Self-collected anterior nasal and saliva specimens vs. health care workercollected nasopharyngeal swabs for the molecular detection of SARS-CoV-2. J Clin Microbiol. (2020) 58:20. doi: 10.1128/JCM.01824-20

20. Iwasaki S, Fujisawa S, Nakakubo S, Kamada K, Yamashita Y, Fukumoto T, et al. Comparison of SARS-CoV-2 detection in nasopharyngeal swab and saliva. $J$ Infection. (2020) 81:145-7. doi: 10.1016/j.jinf.2020.05.071

21. Jamal AJ, Mozafarihashjin M, Coomes E, Powis J, Li AX, Paterson A, et al. Sensitivity of nasopharyngeal swabs and saliva for the detection of severe acute respiratory syndrome coronavirus 2 (SARS-CoV-2). Clin Infect Dis. (2020) 72:1064-6. doi: 10.1101/2020.05.01.20081026

22. Kandel C, Zheng J, McCready J, Serbanescu MA, Racher H, Desaulnier M, et al. Detection of SARS-CoV-2 from saliva as compared to nasopharyngeal swabs in outpatients. Viruses. (2020) 12:1-10. doi: 10.3390/v12111314

23. Landry ML, Criscuolo J, Peaper DR. Challenges in use of saliva for detection of SARS CoV-2 RNA in symptomatic outpatients. J Clin Virol. (2020) 130:13 doi: 10.1016/j.jcv.2020.104567

24. Matic N, Stefanovic A, Leung V, Lawson T, Ritchie G, Li L, et al. Practical challenges to the clinical implementation of saliva for SARS-CoV-2 detection. Eur J Clin Microbiol Infect Dis. (2021) 40:447-50. doi: 10.1007/s10096-020-04090-5

25. McCormick-Baw C, Morgan K, Gaffney D, Cazares Y, Jaworski K, Byrd A, et al. Saliva as an alternate specimen source for detection of SARS-CoV2 in symptomatic patients using cepheid xpert xpress SARS-CoV-2. J Clin Microbiol. (2020) 58:1109-20. doi: 10.1128/JCM.01109-20

26. Miller M, Jansen M, Bisignano A, Mahoney S, Wechsberg C, Albanese N, et al. Validation of a self-administrable, saliva-based RT-qPCR test detecting SARS-CoV-2. medRxiv. (2020). doi: 10.1101/2020.06.05.20122721

27. Moreno-Contreras J, Espinoza MA, Sandoval-Jaime C, Cantú-Cuevas MA, Barón-Olivares H, Ortiz-Orozco OD, et al. Saliva sampling and its direct lysis, an excellent option to increase the number of SARS-CoV-2 diagnostic tests in settings with supply shortages. J Clin Microbiol. (2020) 58:16. doi: 10.1128/JCM.01659-20

28. Pasomsub E, Watcharananan SP, Boonyawat K, Janchompoo P, Wongtabtim G, Suksuwan W, et al. Saliva sample as a non-invasive specimen for the diagnosis of coronavirus disease 2019: a cross-sectional study. Clin Microbiol Infect. (2020) 27:285.e1-4. doi: 10.1016/j.cmi.2020.05.001

29. Ranoa DRE, Holland RL, Alnaji FG, Green KJ, Wang L, Brooke CB, et al. Saliva-based molecular testing for SARS-CoV-2 that bypasses RNA extraction. bioRxiv. (2020). doi: 10.1101/2020.06.18.159434

30. Rao M, Rashid FA, Sabri F, Jamil NN, Zain R, Hashim R, et al. Comparing nasopharyngeal swab and early morning saliva for the identification of SARSCoV-2. Clin Infect Dis. (2020) 2020:ciaa1156. doi: 10.1093/cid/ciaa1156

31. Rutgers. Accelerated emergency use authorization (EUA) summary SARSCoV-2 assay. In: Laboratory CG, editor. Rutgers Clinical Genomics Laboratory TaqPath SARS-CoV-2 Assay EUA Summary. New Jersey, NJ: U.S. Food and Drug Administration (2020). p. 8.

32. Senok A, Alsuwaidi H, Atrah Y, Al Ayedi O, Al Zahid J, Han A, et al. Saliva as an alternative specimen for molecular COVID-19 testing in community settings and population-based screening. Infect Drug Resistance. (2020) 13:3393-9. doi: 10.2147/IDR.S275152

33. Skolimowska K, Rayment M, Jones R, Madona P, Moore LSP, Randell P. Non-invasive saliva specimens for the diagnosis of COVID-19: caution in mild outpatient cohorts with low prevalence. Clin Microbiol Infect. (2020) 26:1711-3. doi: 10.1016/j.cmi.2020.07.015

34. Torres M, Collins K, Corbit M, Ramirez M, Winters CR, Katz L, et al. Comparison of saliva and nasopharyngeal swab SARS-CoV-2 RT-qPCR testing in a community setting. J Infection. (2020) 82:84123. doi: 10.1016/j.jinf.2020.11.015

35. Uwamino Y, Nagata M, Aoki W, Fujimori Y, Nakagawa T, Yokota $\mathrm{H}$, et al. Accuracy and stability of saliva as a sample for reverse transcription PCR detection of SARS-CoV-2. J Clin Pathol. (2021) 74:678. doi: 10.1136/jclinpath-2020-206972

36. Vaz SN, Santana DS, Netto EM, Pedroso C, Wang WK, Santos FDA, et al. Saliva is a reliable, non-invasive specimen for SARS-CoV-2 detection. Brazil J Infect Dis. (2020) 24:422-7. doi: 10.1016/j.bjid.2020.08.001

37. Yokota I, Shane PY, Okada K, Unoki Y, Yang Y, Inao T, et al. Mass screening of asymptomatic persons for SARS-CoV-2 using saliva. Clin Infect Dis. (2020) 2020: ciaa1388. doi: 10.1093/cid/ciaa1388

38. To KK, Tsang OT, Chik-Yan Yip C, Chan KH, Wu TC, Chan JMC, et al. Consistent detection of 2019 novel coronavirus in saliva. Clin Infect Dis. (2020) 71:841-3. doi: 10.1093/cid/ciaa149

39. To KK, Tsang OT, Leung WS, Tam AR, Wu TC, Lung DC, et al. Temporal profiles of viral load in posterior oropharyngeal saliva samples and serum antibody responses during infection by SARSCoV-2: an observational cohort study. Lancet Infect Dis. (2020) 20:565-74. doi: 10.1016/S1473-3099(20)30196-1

40. Kim YI, Kim SG, Kim SM, Kim EH, Park SJ, Yu KM, et al. Infection and rapid transmission of SARS-CoV-2 in ferrets. Cell Host Microbe. (2020) 27:704-9. doi: 10.1016/j.chom.2020.03.023

41. Wyllie AL, Fournier J, Casanovas-Massana A, Campbell M, Tokuyama M, Vijayakumar P, et al. Saliva or nasopharyngeal swab specimens for detection of SARS-CoV-2. N Engl J Med. (2020) 383:1283-6. doi: 10.1056/NEJMc2016359

42. Muhi S, Tayler N, Hoang T, Ballard SA, Graham M, Rojek A, et al. Multisite assessment of rapid, point-of-care antigen testing for the diagnosis of SARS-CoV-2 infection in a low-prevalence setting: a validation and implementation study. Lancet Regional Health Western Pacific. (2021) 9:100115. doi: 10.1016/j.lanwpc.2021.100115

43. Mahase E. Covid-19: 120 million rapid tests pledged to low and middle income countries. BMJ. (2020) 371:3857. doi: 10.1136/bmj.m3857

44. Li L, Chen QY, Li YY, Wang YF, Yang ZF, Zhong NS. Comparison among nasopharyngeal swab, nasal wash, and oropharyngeal swab for respiratory virus detection in adults with acute pharyngitis. BMC Infect Dis. (2013) 13:281. doi: 10.1186/1471-2334-13-281

45. Frazee BW, Rodríguez-Hoces de la Guardia A, Alter H, Chen CG, Fuentes EL, Holzer AK, et al. Accuracy and discomfort of different types of intranasal specimen collection methods for molecular influenza testing in emergency department patients. Ann Emerg Med. (2018) 71:50917. doi: 10.1016/j.annemergmed.2017.09.010

46. Marty FM, Chen K, Verrill KA. How to obtain a nasopharyngeal swab specimen. N Engl J Med. (2020) 383:14. doi: 10.1056/NEJMc2015949

47. Lancet T. COVID-19: protecting health-care workers. Lancet. (2020) 395:922. doi: 10.1016/S0140-6736(20)30644-9 
48. Qian Y, Zeng T, Wang H, Xu M, Chen J, Hu N, et al. Safety management of nasopharyngeal specimen collection from suspected cases of coronavirus disease 2019. Int J Nurs Sci. (2020) 7:153-6. doi: 10.1016/j.ijnss.2020. 03.012

49. Nkengasong JN, Mankoula W. Looming threat of COVID19 infection in Africa: act collectively, and fast. Lancet. (2020) 395:841-2. doi: 10.1016/S0140-6736(20)30464-5

50. Bustin SA, Nolan T. Pitfalls of quantitative real-time reverse-transcription polymerase chain reaction. J Biomol Techniq. (2004) 15:155-66.

51. Buonfrate D, Requena-Mendez A, Angheben A, Cinquini M, Cruciani M, Fittipaldo A, et al. Accuracy of molecular biology techniques for the diagnosis of Strongyloides stercoralis infectionA systematic review and meta-analysis. PLoS Neglect Trop Dis. (2018) 12:e0006229. doi: 10.1371/journal.pntd.0006229

52. Wyllie AL, Fournier J, Casanovas-Massana A, Campbell M, Tokuyama M, Vijayakumar P, et al. Saliva is more sensitive for SARS-CoV-2 detection in COVID-19 patients than nasopharyngeal swabs. medRxiv. (2020). doi: 10.1101/2020.04.16.20067835

53. Yang Y, Peng F, Wang R, Guan K, Jiang T, Xu G, et al. The deadly coronaviruses: the 2003 SARS pandemic and the 2020 novel coronavirus epidemic in China. J Autoimmunity. (2020) 109:102434. doi: 10.1016/j.jaut.2020.102434

54. Woloshin S, Patel N. False negative tests for SARS-CoV-2 infection - challenges and implications. (2020) 383:e38. doi: 10.1056/NEJMp 2015897

55. Chen JH, Yip CC, Poon RW, Chan KH, Cheng VC, Hung IF, et al. Evaluating the use of posterior oropharyngeal saliva in a point-of-care assay for the detection of SARS-CoV-2. Emerg Microbes Infect. (2020) 9:13569. doi: 10.1080/22221751.2020.1775133

56. Chu AW, Chan WM, Ip JD, Yip CC, Chan JF, Yuen KY, et al. Evaluation of simple nucleic acid extraction methods for the detection of SARS-CoV-2 in nasopharyngeal and saliva specimens during global shortage of extraction kits. J Clin Virol. (2020) 129:104519. doi: 10.1016/j.jcv.2020.104519

57. Zheng S, Fan J, Yu F, Feng B, Lou B, Zou Q, et al. Viral load dynamics and disease severity in patients infected with SARS-CoV-2 in Zhejiang province, China, January-March 2020: retrospective cohort study. BMJ. (2020) 369:1443. doi: 10.1136/bmj.m1443

58. Rao M, Rashid FA, Sabri F, Jamil NN, Seradja V, Abdullah NA, et al. COVID-19 screening test by using random oropharyngeal saliva. J Medical Virol. (2021) 93:2461-6. doi: 10.1002/jmv.26773

59. Procop GW, Shrestha NK, Vogel S, Van Sickle K, Harrington S, Rhoads DD, et al. A direct comparison of enhanced saliva to nasopharyngeal swab for the detection of SARS-CoV-2 in symptomatic patients. J Clin Microbiol. (2020) 58:1-6. doi: 10.1128/JCM.01946-20

60. Arias-Bujanda N, Regueira-Iglesias A, Balsa-Castro C, Nibali L. Accuracy of single molecular biomarkers in saliva for the diagnosis of periodontitis: a systematic review and meta-analysis. J Clin Periodontol. (2020) 47:218. doi: $10.1111 /$ jcpe. 13202

61. Siegler AJ, Hall E, Luisi N, Zlotorzynska M, Wilde G, Sanchez T, et al. Willingness to seek laboratory testing for SARS-CoV-2 with home, drive-through, and clinic-based specimen collection locations. medRxiv. (2020). doi: 10.1101/2020.05.06.20093005

62. Ali N, Rampazzo RCP, Costa ADT, Krieger MA. Current nucleic acid extraction methods and their implications to point-of-care diagnostics. BioMed Res Int. (2017) 2017:1-13. doi: 10.1155/2017/9306564

63. Gandhi V, O’Brien MH, Yadav S. High-quality and high-yield RNA extraction method from whole human saliva. Biomarker Insights. (2020) 15:1-9. doi: 10.1177/1177271920929705
64. Yu L, Wu S, Hao X, Dong X, Mao L, Pelechano V, et al. Rapid detection of COVID-19 coronavirus using a reverse transcriptional loop-mediated isothermal amplification (RT-LAMP) diagnostic platform. Clin Chem. (2020) 66:975-7. doi: 10.1093/clinchem/hvaa102

65. Kitagawa Y, Orihara Y, Kawamura R, Imai K, Sakai J, Tarumoto N, et al. Evaluation of rapid diagnosis of novel coronavirus disease (COVID19) using loop-mediated isothermal amplification. J Clin Virol. (2020) 129:104446. doi: 10.1016/j.jcv.2020.104446

66. Yamazaki W, Matsumura Y, Thongchankaew-Seo U, Yamazaki Y, Nagao M. Development of a point-of-care test to detect SARS-CoV-2 from saliva which combines a simple RNA extraction method with colorimetric reverse transcription loop-mediated isothermal amplification detection. J Clin Virol. (2021) 136:104760. doi: 10.1016/j.jcv.2021.104760

67. Lalli MA, Langmade JS, Chen X, Fronick CC, Sawyer CS, Burcea LC et al. Rapid and extraction-free detection of SARS-CoV-2 from saliva by colorimetric reverse-transcription loop-mediated isothermal amplification. Clin Chem. (2021) 67:415-24. doi: 10.1093/clinchem/hvaa267

68. Nagura-Ikeda M, Imai K, Tabata S, Miyoshi K, Murahara N, Mizuno T, et al. Clinical evaluation of self-collected saliva by quantitative reverse transcription-PCR (RT-qPCR), direct RT-qPCR, reverse transcription-loopmediated isothermal amplification, and a rapid antigen test to diagnose COVID-19. J Clin Microbiol. (2020) 58:1-9. doi: 10.1128/JCM.01438-20

69. Au CH, Chan WS, Lam HY, Ho DN, Lam SYM, Zee JST, et al. Genome sequences of SARS-CoV-2 strains detected in Hong Kong. Microbiol Resource Announcements. (2020) 9:1-3. doi: 10.1128/MRA.00697-20

70. Teo AKJ, Choudhury Y, Tan IB, Cher CY, Chew SH, Wan ZY, et al. Saliva is more sensitive than nasopharyngeal or nasal swabs for diagnosis of asymptomatic and mild COVID-19 infection. Sci Rep. (2021) 11:3134. doi: 10.1038/s41598-021-82787-z

71. Chan WM, Ip JD, Chu AW, Yip CC, Lo LS, Chan KH, et al. Identification of nsp1 gene as the target of SARS-CoV-2 real-time RT-PCR using nanopore whole-genome sequencing. J Medical Virol. (2020) 92:272534. doi: $10.1002 / j m v .26140$

72. Ip JD, Kok KH, Chan WM, Chu AW, Wu WL, Yip CC, et al. Intra-host non-synonymous diversity at a neutralizing antibody epitope of SARS-CoV-2 spike protein N-terminal domain. Clin Microbiol Infect. (2020) 2020:S1198743X(20):30661-3. doi: 10.1016/j.cmi.2020.10.030

73. Zhang X, Tan Y, Ling Y, Lu G, Liu F, Yi Z, et al. Viral and host factors related to the clinical outcome of COVID-19. Nature. (2020) 583:43740. doi: 10.1038/s41586-020-2355-0

Conflict of Interest: RS-S, TC, LG, LC-S, and MM are inventors of patents related to the use of photonic devices for COVID-19 diagnosis using saliva and nasopharyngeal samples titled, Spectral profile for COVID-19 diagnostic, use of the same, method, system, and platform to COVID-19 diagnosis-BR 102020 0109928.

The remaining authors declare that the research was conducted in the absence of any commercial or financial relationships that could be construed as a potential conflict of interest.

Copyright (c) 2021 Caixeta, Oliveira, Cardoso-Sousa, Cunha, Goulart, Martins, Marin, Jardim, Siqueira and Sabino-Silva. This is an open-access article distributed under the terms of the Creative Commons Attribution License (CC BY). The use, distribution or reproduction in other forums is permitted, provided the original author(s) and the copyright owner(s) are credited and that the original publication in this journal is cited, in accordance with accepted academic practice. No use, distribution or reproduction is permitted which does not comply with these terms. 